\title{
Benchmarking of Siemens Linac in Electron Modes: 8-14 MeV Electron Beams
}

\author{
Dowlatabadi H. ${ }^{1}$, Mowlavi A. A. ${ }^{2,3 *}$, Ghorbani M.4, \\ Mohammadi S. ${ }^{1}$, Akbari F. ${ }^{5}$
}

\begin{abstract}
Background: Radiation therapy using electron beams is a promising method due to its physical dose distribution. Monte Carlo (MC) code is the best and most accurate technique for forespeaking the distribution of dose in radiation treatment of patients.

Material and Methods: We report an MC simulation of a linac head and depth dose on central axis, along with profile calculations. The purpose of the present research is to carefully analyze the application of MC methods for the calculation of dosimetric parameters for electron beams with energies of $8-14 \mathrm{MeV}$ at a Siemens Primus linac. The principal components of the linac head were simulated using MCNPX code for different applicators.

Results: The consequences of measurements and simulations revealed a good agreement. Gamma index values were below 1 for most points, for all energy values and all applicators in percent depth dose and dose profile computations. A number of states exhibited rather large gamma indices; these points were located at the tail of the percent depth dose graph; these points were less used in in radiotherapy. In the dose profile graph, gamma indices of most parts were below 1 . The discrepancies between the simulation results and measurements in terms of $Z_{\text {max }}, R_{90}, R_{80}$ and $R_{50}$ were insignificant. The results of Monte Carlo simulations showed a good agreement with the measurements.
\end{abstract}

Conclusion: The software can be used for simulating electron modes of a Siemens Primus linac when direct experimental measurements are not feasible.

\section{Keywords}

Radiotherapy, Electron Mode, Monte Carlo Simulation, Siemens Primus Linac, Gamma Function

\section{Introduction}

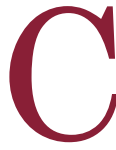

ancer-related mortality rate exceeds those associated with other conditions, such as malaria and human immunodeficiency virus (HIV)[1]. Radiation therapy has long been considered appropriate for treating cancers, and one radiotherapy approach uses electrons $[2,3]$. Electron beams are advantageous, as they ensure dose monotony in the target volume and minimize the dose to deeper healthy tissues owing to the rapid dose fall-off beyond the tumor [4]. MC methods have been widely used in radiotherapy [5-8].

Several MC software have been extensively used for radiotherapy simulations, such as the Electron Gamma Shower (EGS4) package, MC package, Geometry and Tracking (GEANT4) package and the PENEL-
${ }^{1}$ Physics Department,

School of Sciences,

Payame Noor University

of Mashhad, Mashhad,

Iran

2Physics Department,

School of Sciences,

Hakim Sabzevari Univer-

sity, Sabzevar, Iran

${ }^{3}$ ICTP, Associate Federa-

tion Scheme, Medical

Physics Field, Trieste,

Italy

${ }^{4}$ Biomedical Engineer-

ing and Medical Phys-

ics Department, Fac-

ulty of Medicine, Shahid

Beheshti University of

Medical Sciences, Teh-

ran, Iran

${ }^{5}$ Medical Physics Depart-

ment, Reza Radiation

Oncology Center, Mash-

had, Iran

* corresponding authors:

A. A. Mowlavi

Physics Department,

School of Sciences,

Hakim Sabzevari Uni-

versity, Tohid Shahr,

Sabzevar, Iran

E-mail:amowlavi@hsu.

ac.ir

Received: 06 July 2017

Accepted: 27 July 2017 
OPE package. One of the most popular MC software packages used in a large number of applications is the MCNPX package [9]; the present study was performed using this package. Several scientists have used MC methods to simulate and specify the characteristics of electron beams in radiotherapy. Lalic et al. [10] used MC simulations to enumerate depth dose data on central axis with energies of 6 - $12 \mathrm{MeV}$, generated by a Varian linear accelerator (linac) in water. Antolak et al. [11] used $\mathrm{MC}$ calculations to study the effect of scattering foil parameters on electron beams. Kapur et al. [12] applied the MC method to calculate and analyze the production factors of electron beams used in radiotherapy.

Nedaie et al. [13] implemented simulations to acquire dose repartitions produced by an ELEKTA linac at beam energies of $15 \mathrm{MeV}$ and $8 \mathrm{MeV}$, for applicator with dimensions $10 \times 10 \mathrm{~cm}^{2}$. The discrepancy of the measurements and calculations was within $2 \%$, for 8 $\mathrm{MeV}$ and $15 \mathrm{MeV}$ electron beams. The purpose of the present research was to simulate beams with energies in the 8-14 MeV range, for a Siemens Primus linac, and to validate the simulations by comparing the results of these simulations with the measured data.

\section{Material and Methods}

\section{Simulation of Linac}

In this study, a linac installed at the Reza Radiation Oncology Center was simulated using MCNPX software. The Siemens Primus medical linac has two treatment modes: photon and electron. This machine has two photon energies: $6 \mathrm{MeV}$ and $15 \mathrm{MeV}$, and works with four nominal electron energies: 8, 10, 12 and 14 $\mathrm{MeV}$. In this study, electron modes of this device were simulated. The linac head geometry was modelled using MCNPX (version 2.7.0) software [14]. The optimized energy of the electron spectrum was within $\pm 0.2 \mathrm{MeV}$ energy range, compared with the manufacturerprovided spectrum. This choice was justified by the agreement between the computer-simulation-specified build-up depths and empirical measurements [15].

Although many studies have been reported for linacs in the photon mode, only a few studies are performed on electron beams. Siemens Primus medical linac was selected for the present study. The schematic view of linac head is illustrated in Figure 1 [16]. The head of the linac subtends the following components: $Y$ and $X$ jaws, an electron dose chamber, a primary foil, an applicator and a secondary foil. The primary foil is made of brass and Ledloy. The chamber is made of gold, air and Kapton, and the jaws is made of steel. The applicators are comprised of six parts: a tray, a scraper, a body, a collimator, a shield and a plate. The tray, the body and the plate are made of aluminum, and the shield is made of stainless steel while the collimator is made of brass [16]. Complying with the task group report No. 105 (TG 105) by the American Society of Physicists, MC simulations should be performed
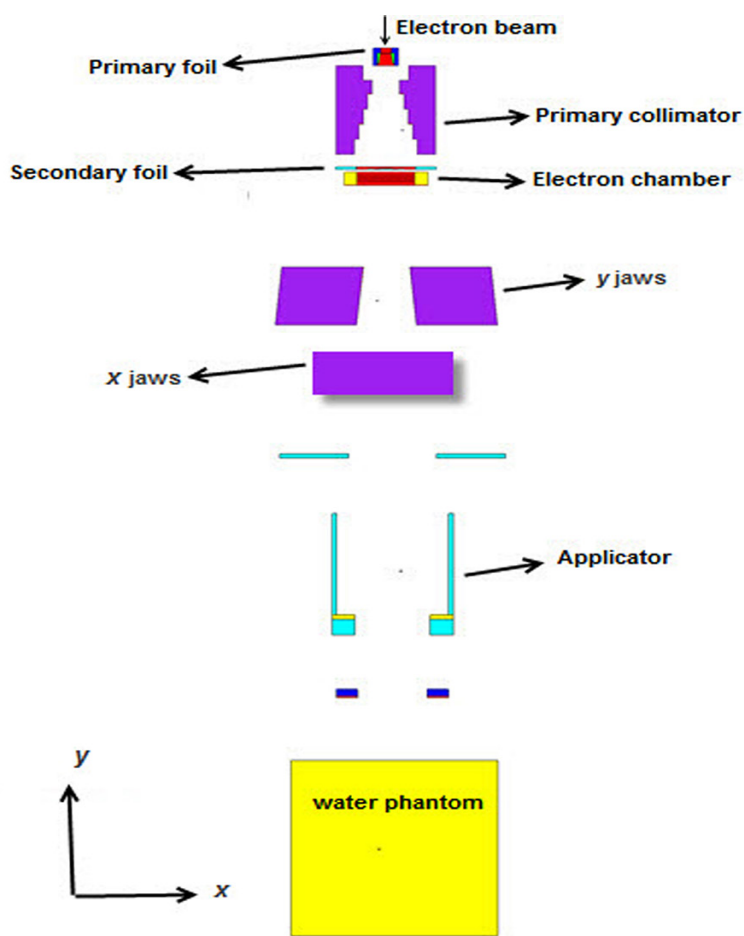

Figure 1: Schematic view of Siemens Primus accelerator in electron mode ( $\mathrm{Y}-\mathrm{X}$ view) with a water phantom 
under the same conditions as measurements [17].

To estimate the precision of dose calculations procured by the MC model of a linear accelerator's head, measurement data have to be collected. For this purpose, empirical measurements of the profile and percentage depth dose (PDD) were done by a Scanditronix system. Measurements were carried out in a water phantom by a silicon detector. Calculations were done with energies of $8-14$ $\mathrm{MeV}$, generated by the Siemens linac. The MC simulations in the present research were run on a computer with a processor, $4.00 \mathrm{GHz}$, featuring a 64-bit operating system. Square fields were shaped for four applicator area sizes: $10 \times 10 \mathrm{~cm}^{2}, 15 \times 15 \mathrm{~cm}^{2}, 20 \times 20 \mathrm{~cm}^{2}$ and $25 \times 25 \mathrm{~cm}^{2}$. Benchmarking comparisons were done by comparing the simulation PDD data for four applicators listed above with the corresponding measured data. Another benchmark amounted to compare the dose profile data for different depths and energies, for two applicators $\left(10 \times 10 \mathrm{~cm}^{2}\right.$ and $\left.20 \times 20 \mathrm{~cm}^{2}\right)$, with the corresponding measured data.

In addition, to continue the research process, a water phantom was simulated. Phantom was considered as a $50 \mathrm{~cm} \times 50 \mathrm{~cm} \times 50 \mathrm{~cm}$ cube, the surface of which was $100 \mathrm{~cm}$ away from the source. Variance reduction methods included introducing an energy cut-off and cell importance. Cell importance for both electrons and photons was set as 1 for all simulation cells, while it was defined equal to 100 for tally cells in the phantom. Energy cut-off for electrons and photons was considered to be $500 \mathrm{keV}$. Each file was run for $2 \times 10^{8}$ particle. *F8 tally in program was used to calculate the energy deposited by electrons and the output of this calculation was divided by the mass of the tally corresponding cells to obtain the absorbed dose.

To calculate PDD, some 2-mm-tall and 1-cm-radius cylinders were selected for fields with different sizes. To compute the profile inside the phantom, cylinders with the radius of
$2 \mathrm{~mm}$ and length of $2 \mathrm{~mm}$ on $X$ axis direction were arrayed along $X$ axis at different depths of the phantom for different field sizes, $X$ axis being parallel to the surface of the phantom. PDD amounts were calculated for all four energies for four applicators listed above. Moreover, dose profiles were calculated for two depths and the four above-mentioned applicators for all energies.

Comparison of Experimental and Computational Values of the Profile and PDD by Gamma Functi

Comparison of experimental and computational values of the profile and PDD were made by computing the gamma function software. This software is beneficial for comparing two distributions of dose. This function has two criteria previously used for comparing two dose distributions: the percentage dose difference (DD) (offered in \%) and the distance to settlement (DTA) (offered in mm). The gamma index (function) takes on values between 0 and 1. Gamma function values in the $0-1$ range are considered as a pass, while gamma function values larger than 1 are considered a failure. Gamma software provided by DOSI soft company. DD and DTA were set $3 \%$ and $2 \mathrm{~mm}$ in gamma calculations, respectively [18 -21].

\section{Results and Discussion}

In this research, MC method was utilized to compute the distributions of dose with energies $8-14 \mathrm{MeV}$, generated by a Siemens Primus linac; characteristics such as the percentage depth dose graph on central axis and profiles were computed using MC method. The simulated PDD values for four applicators listed above were compared with those measured for electron beams with energies of 8-14 $\mathrm{MeV}$; the results of this comparison are shown in Figure 2. It should be mentioned that PDD values for 10,12 and $14 \mathrm{MeV}$ energy beams were multiplied by $1.1,1.2$ and 1.3 , respectively, to distinguish them from the PDD for 

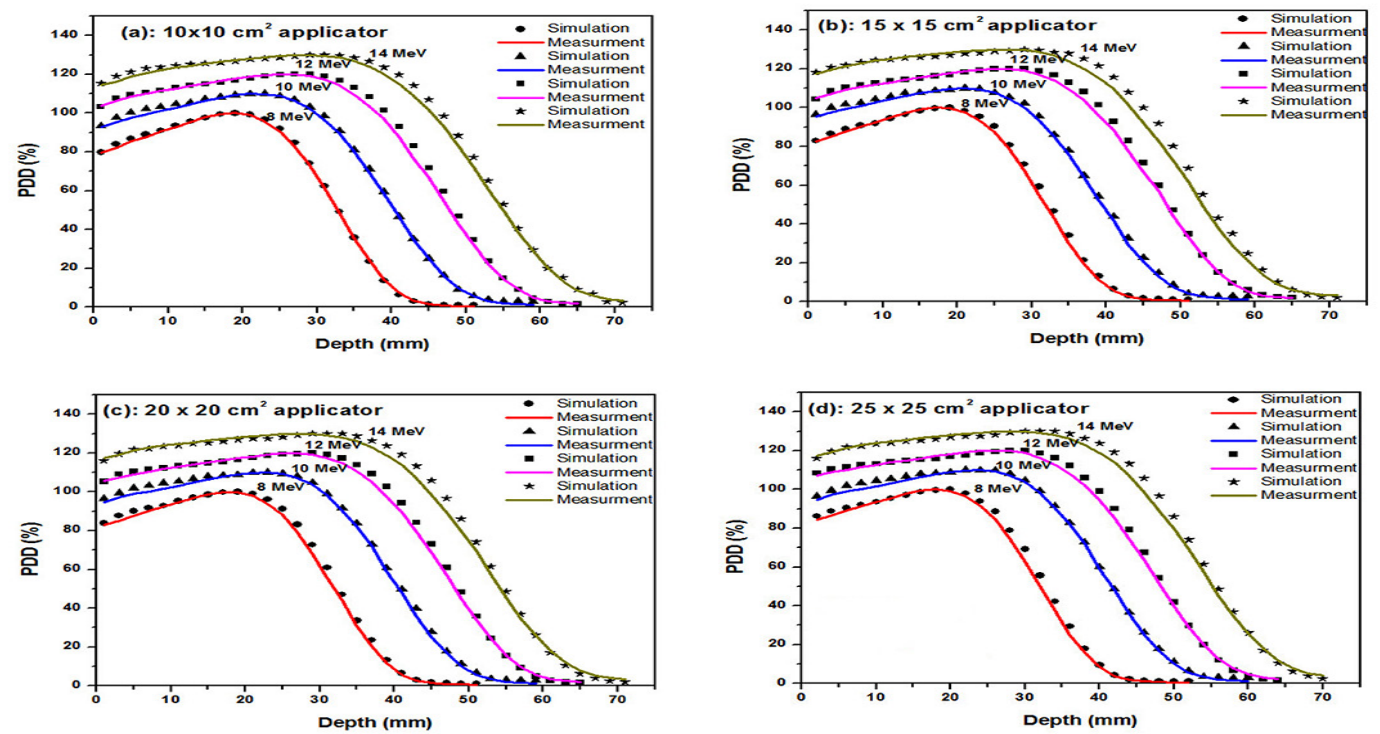

Figure 2: PDD values from simulations and measurements, vs. depth, for 8- $14 \mathrm{MeV}$ energy. The results shown for (a) the $10 \times 10 \mathrm{~cm}^{2}$ applicator; (b) the $15 \times 15 \mathrm{~cm}^{2}$ applicator; (c) the 20 $\times 20 \mathrm{~cm}^{2}$ applicator; (d) the $25 \times 25 \mathrm{~cm}^{2}$ applicator. To avoid overlapping of the curves, the PDD values for the 10,12 , and $14 \mathrm{MeV}$ energies were multiplied by $1.1,1.2$, and 1.3 , respectively

$8 \mathrm{MeV}$. The applicator with dimension $10 \times 10$ $\mathrm{cm}^{2}$ was used as a reference field size to match the obtained PDD curves. Of course, the $25 \times$ $25 \mathrm{~cm}^{2}$ applicator was also examined because its large field size was the most sensitive to the treatment head parameter in this step [22].
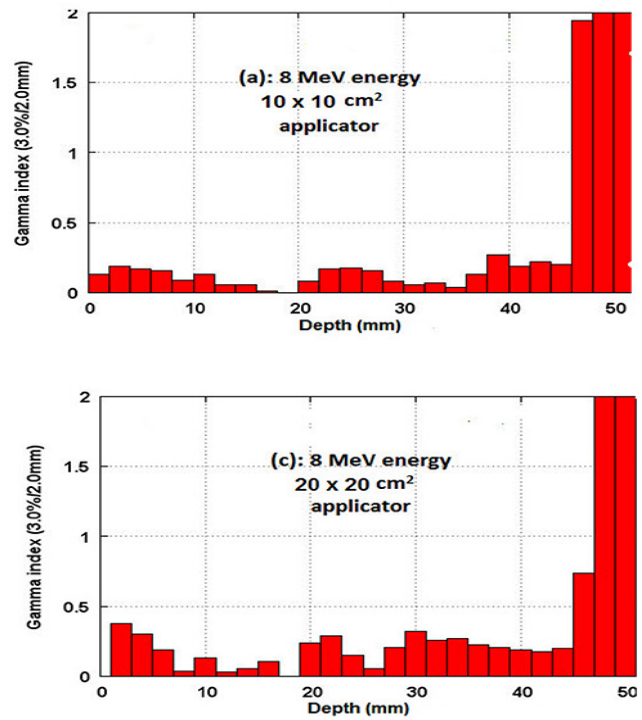

All simulated PDD values were compared with those measured for energies of $8-14$ $\mathrm{MeV}$, in terms of their gamma functions. The gamma function values for PDD distributions vs. the depth of phantom (mm) are shown in Figures 3-6 for various applicators and ener-
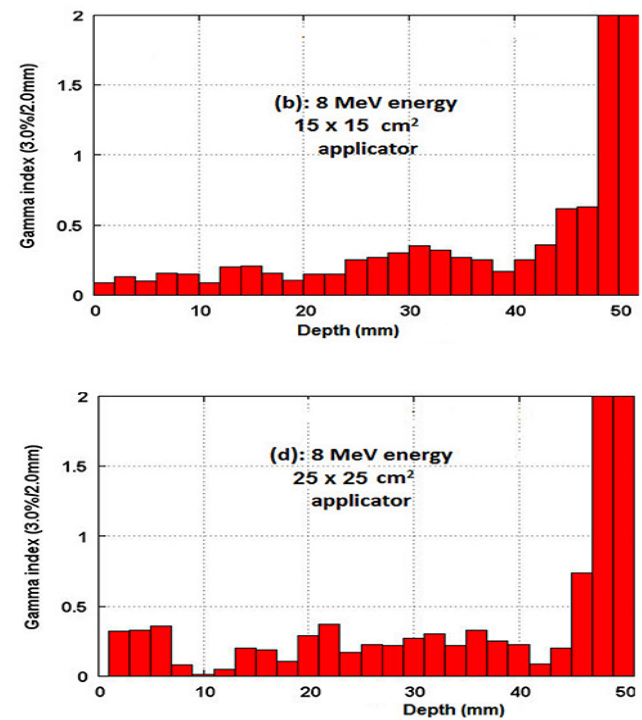

Figure 3: Gamma function values vs. depth in the phantom $(\mathrm{mm})$, for the $8 \mathrm{MeV}$ energy electron beam, for the: (a) $10 \times 10 \mathrm{~cm}^{2}$, (b) $15 \times 15 \mathrm{~cm}^{2}$, (c) $20 \times 20 \mathrm{~cm}^{2}$, and (d) $25 \times 25 \mathrm{~cm}^{2}$ applicators 

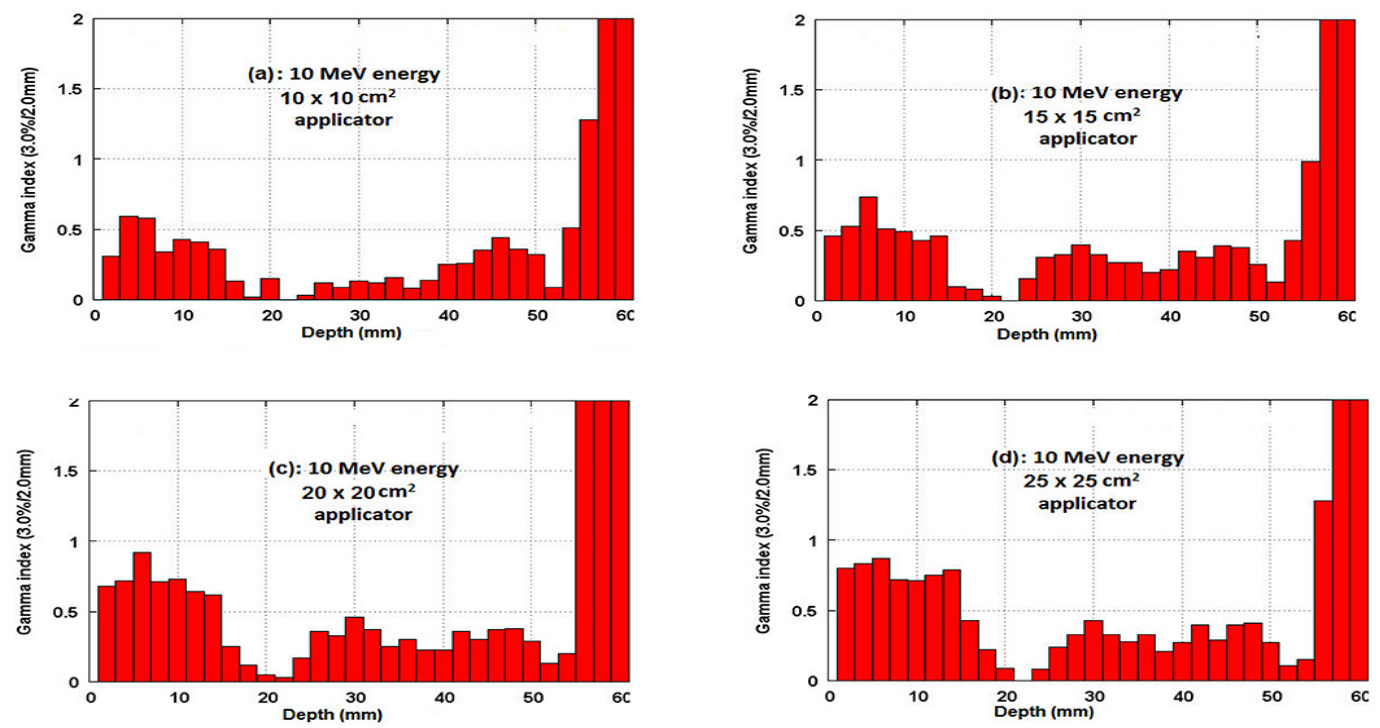

Figure 4: Gamma index values vs. depth in the phantom $(\mathrm{mm})$, for the $10 \mathrm{MeV}$ energy electron beam, for the: (a) $10 \times 10 \mathrm{~cm}^{2}$, (b) $15 \times 15 \mathrm{~cm}^{2}$, (c) $20 \times 20 \mathrm{~cm}^{2}$, and (d) $25 \times 25 \mathrm{~cm}^{2}$ applicators

gies. The analogies were based on gamma index computations, and the gamma value was under 1 for most data points in the chart. A gamma value equal to or less than 1 implies that the two compared dose data sets are in agreement [18]. Despite this agreement, there were a number of points for which the gamma value was above 1 . Regarding PDD, the maximal correspondence between measured and simulated data was obtained for the $15 \times 15$ $\mathrm{cm}^{2}$ and $10 \times 10 \mathrm{~cm}^{2}$ applicators and $12 \mathrm{MeV}$ energy beams, and also for all applicators with $8 \mathrm{MeV}$ energy beam. The maximal disagreement between simulated and measured data was observed for the $20 \times 20 \mathrm{~cm}^{2}$ and $15 \times 15$ $\mathrm{cm}^{2}$ applicators in the case of $14 \mathrm{MeV}$ energy beam. In the graph of the gamma index for PDD, most points are below 1, except for the
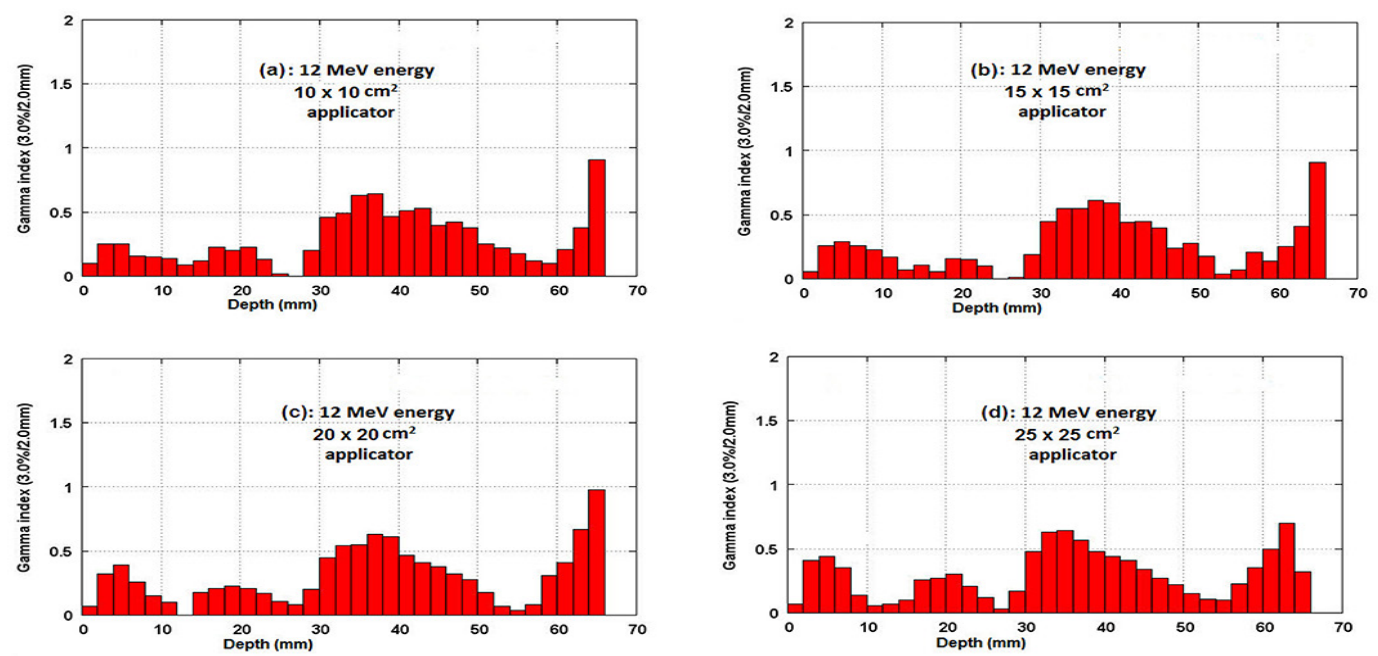

Figure 5: Gamma index values vs. depth in phantom $(\mathrm{mm})$, for the $12 \mathrm{MeV}$ energy electron beam, for the: (a) $10 \times 10 \mathrm{~cm}^{2}$, (b) $15 \times 15 \mathrm{~cm}^{2}$, (c) $20 \times 20 \mathrm{~cm}^{2}$, and (d) $25 \times 25 \mathrm{~cm}^{2}$ applicators 

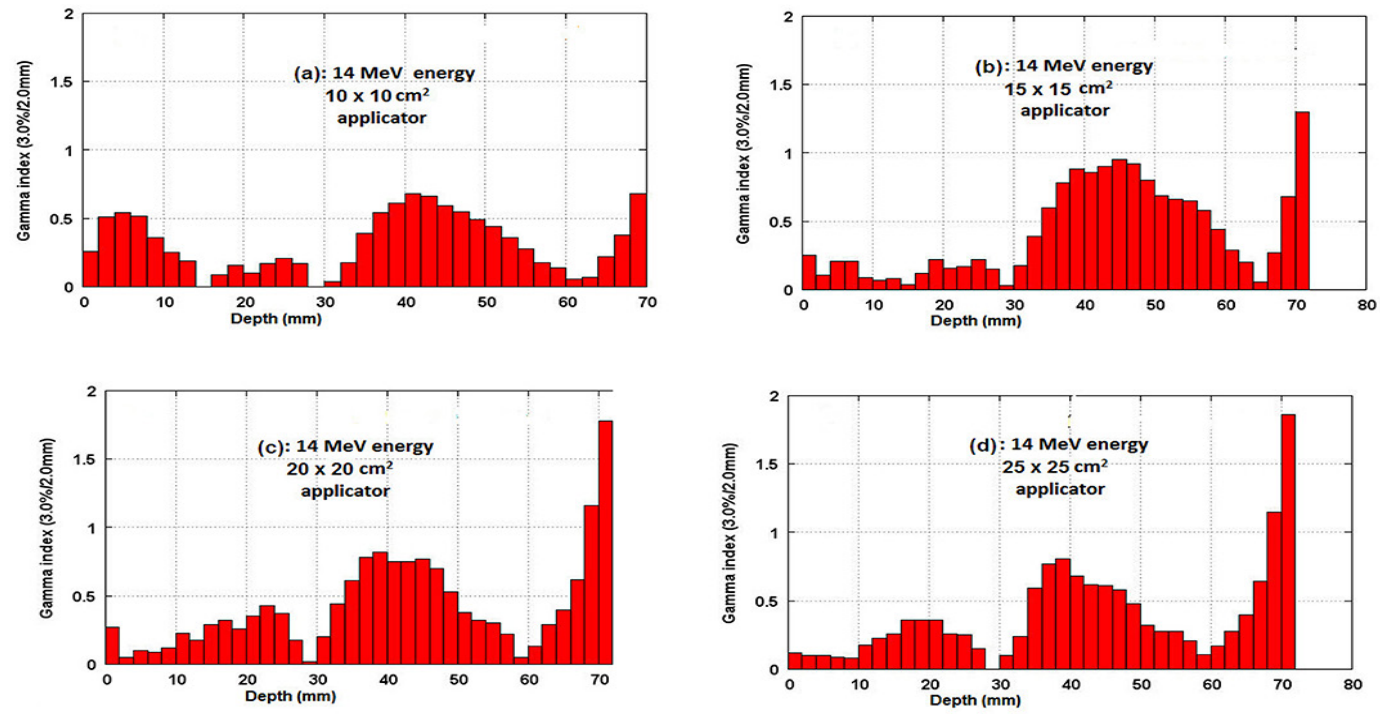

Figure 6: Gamma index values vs. depth in phantom $(\mathrm{mm})$, for the $14 \mathrm{MeV}$ energy electron beam, for the: (a) $10 \times 10 \mathrm{~cm}^{2}$, (b) $15 \times 15 \mathrm{~cm}^{2}$, (c) $20 \times 20 \mathrm{~cm}^{2}$, and (d) $25 \times 25 \mathrm{~cm}^{2}$ applicators

tails of the curves; these points are located on the tail of the PDD graph; these points are not used in therapy. For the energy of $8 \mathrm{MeV}$, the maximal value of the MC statistical uncertainty for the PDD was 3.2\% which was located at the curve's tail; the minimal value of the MC statistical uncertainty was $0.31 \%$ which was located in the build-up area and before it. For the energy of $10 \mathrm{MeV}$, the maximal value of the MC statistical uncertainty for the PDD was $2.1 \%$ which was located at the curve's tail; the minimal value of the MC statistical uncertainty was $0.4 .1 \%$ that was located in the buildup region and before it. For the beam energies of $12 \mathrm{MeV}$ and $14 \mathrm{MeV}$, the maximal value of the MC statistical uncertainty for the PDD was $1.2 \%$ located at the curve's tail curve; the minimal value of the MC statistical uncertainty was $0.23 \%$ located in the build-up region and before it.

The dose profiles for the $10 \times 10 \mathrm{~cm}^{2}$ and $20 \times 20 \mathrm{~cm}^{2}$ applicators for different depths were plotted and the results are shown in Figures 7 and 8 . All of the simulated PDD values were compared with those measured for 8 - $14 \mathrm{MeV}$ energy in terms of their gamma functions. Gamma values are shown in Fig- ure 9 vs. the off-axis distance of the phantom $(\mathrm{mm})$, for various applicators and energies. In the graph of the gamma index for dose profiles, most data points reveal gamma values below 1, except for the dose profile curve for the $14 \mathrm{MeV}$ energy beam. For this curve, some data points have gamma index values above 1. The disagreement might stem from a small inexactitude in modelling the scattering foil which yields a wrong prediction of the scattered dose.

The results indicate that simulations and measurements are in good agreement. In this work, several depth values describing the PDD chart were calculated, including $\mathrm{R}_{80}, \mathrm{R}_{50}, \mathrm{R}_{90}$ and $Z_{\max }$. The values of $R_{90}$ and $R_{50}$ for simulations and measurements and their difference are listed in Tables 1 and 2 for the applicator with dimensions of $10 \times 10 \mathrm{~cm}^{2}$. The simulated and measured data show good agreement. The differences between the measured and simulated $\mathrm{Z}_{\max }, \mathrm{R}_{90}, \mathrm{R}_{80}$ and $\mathrm{R}_{50}$ values are negligible. The accuracy of the simulations is $\sim 2 \%$.

\section{Conclusion}

In this study, MC technique was used to 

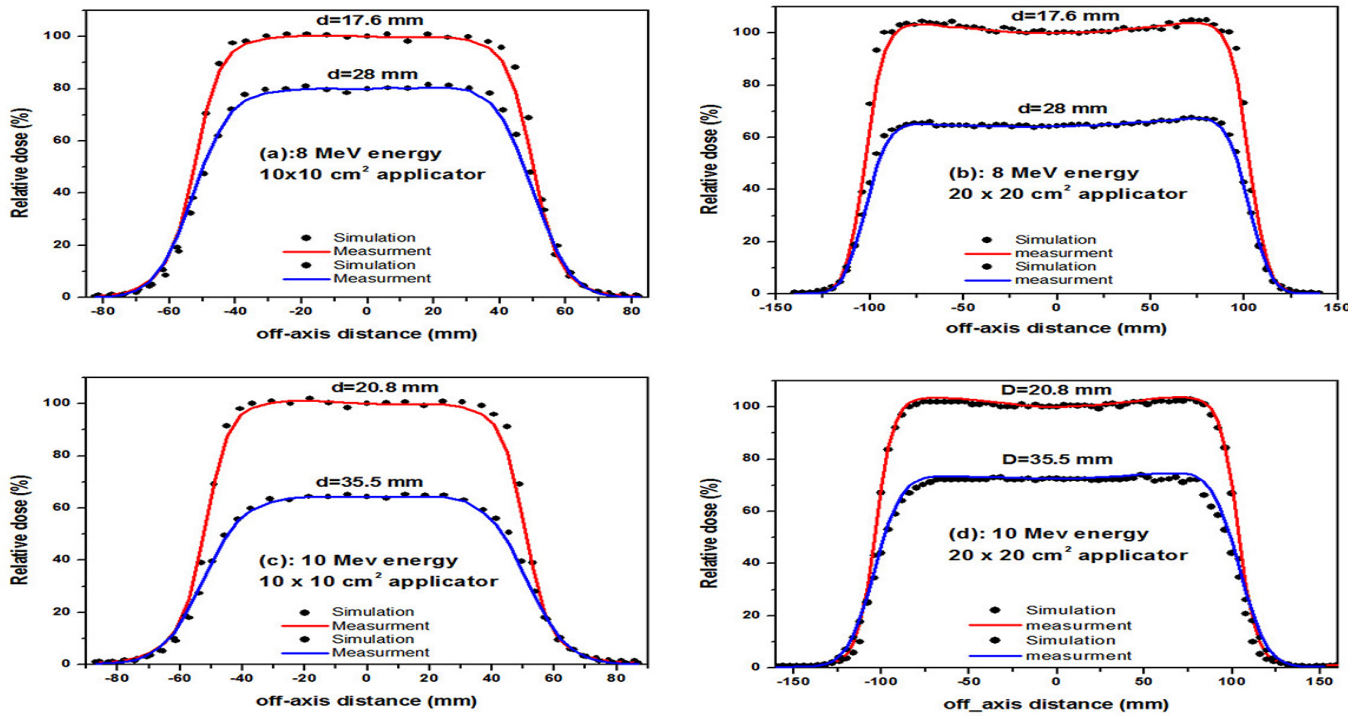

Figure 7: Measured and calculated profiles at different depths, for different applicators and energies. The panels (a) and (b) show the results for the $8 \mathrm{MeV}$ energy, the $10 \times 10 \mathrm{~cm}^{2}$ and $20 \times$ $20 \mathrm{~cm}^{2}$ applicators, respectively. The panels (c) and (d) show the results for $10 \mathrm{MeV}$ energy, for the $10 \times 10 \mathrm{~cm}^{2}$ and $20 \times 20 \mathrm{~cm}^{2}$ applicators, respectively

compute the dose distributions for $8-14 \mathrm{MeV}$ energy generated by a Siemens linac; characteristics such as the percentage depth dose on central axis graph and profiles were computed.
The purpose of this research was to determine the applicability of MC techniques to calculations and analyses of dosimetry parameters for electron beams with energies of $8-14 \mathrm{MeV}$,
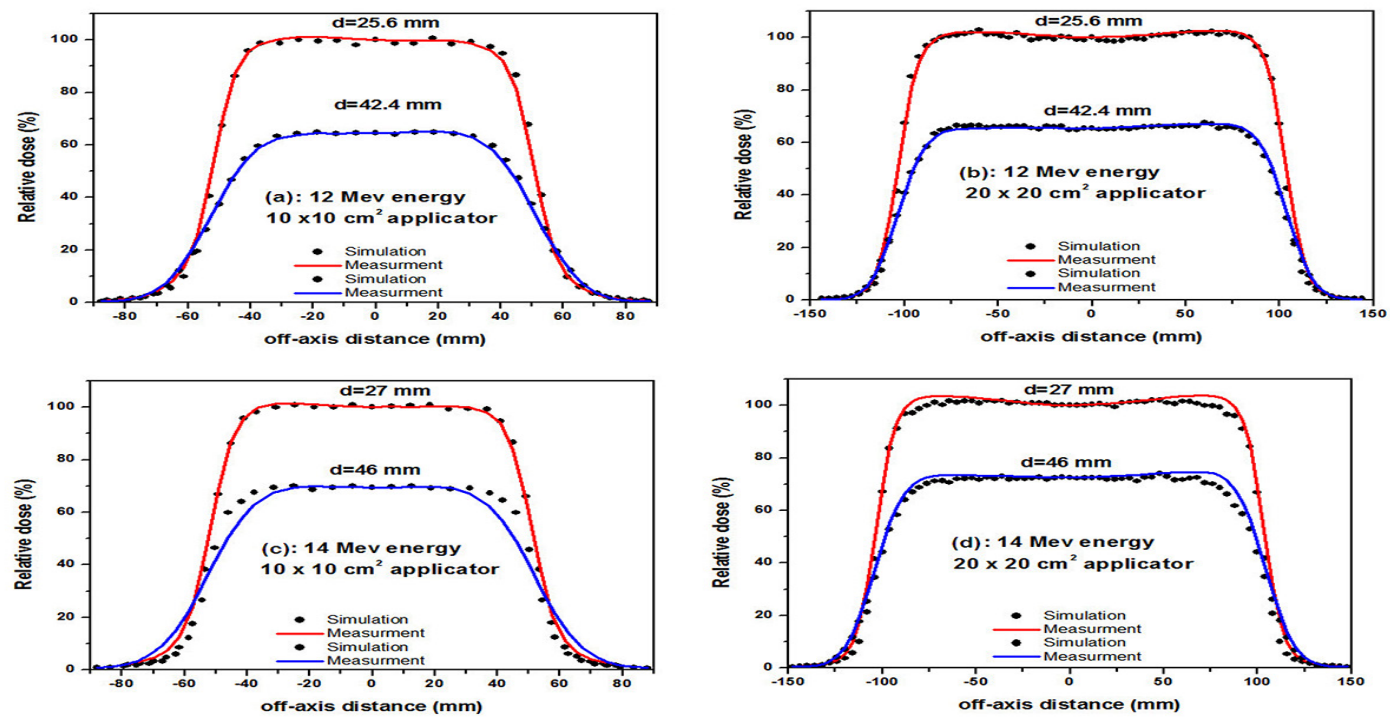

Figure 8: Measured and calculated profiles at different depths, for different applicators and energies. The panels (a) and (b) show the results for the $12 \mathrm{MeV}$ energy, the $10 \times 10 \mathrm{~cm}^{2}$ and $20 \times$ $20 \mathrm{~cm}^{2}$ applicators, respectively. The panels (c) and (d) show the results for the $14 \mathrm{MeV}$ energy, for the $10 \times 10 \mathrm{~cm}^{2}$ and $20 \times 20 \mathrm{~cm}^{2}$ applicators, respectively 

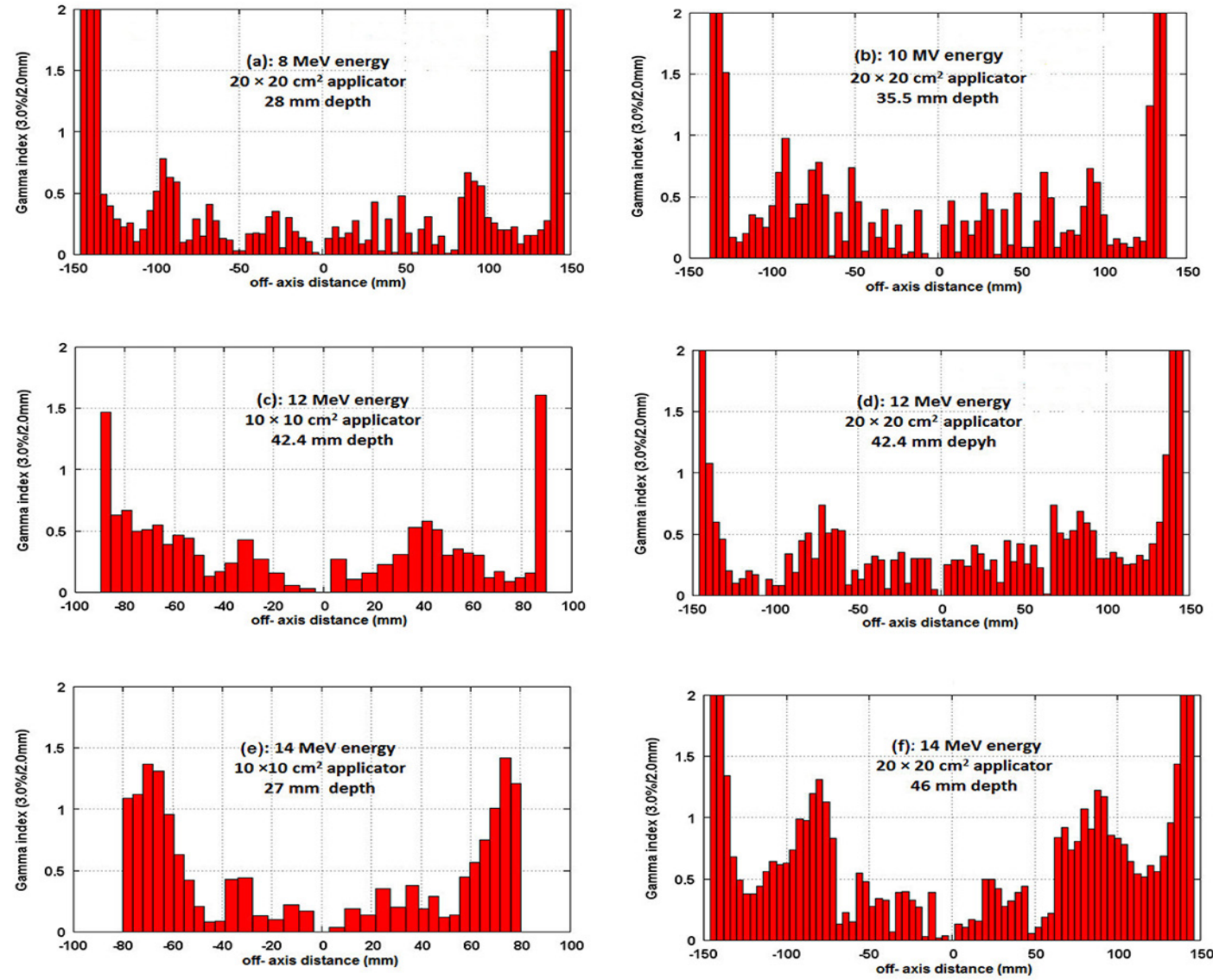

Figure 9: Gamma index values vs. the off-axis distance in phantom $(\mathrm{mm})$, for different applicators and energies: (a) $8 \mathrm{MeV}, 20 \times 20 \mathrm{~cm}^{2}$; (b) $10 \mathrm{MeV}, 20 \times 20 \mathrm{~cm}^{2}$; (c) $12 \mathrm{MeV}, 10 \times 10 \mathrm{~cm}^{2}$; (d) $12 \mathrm{MeV}, 20 \times 20 \mathrm{~cm}^{2}$; (e) $14 \mathrm{MeV}, 10 \times 10 \mathrm{~cm}^{2}$; and (f) $14 \mathrm{MeV}, 20 \times 20 \mathrm{~cm}^{2}$

Table 1: $Z_{\text {max }}, R_{90}, R_{80}$ and $R_{50}$ values computed from $M C$ simulations and measurements, for the $10 \times 10 \mathrm{~cm}^{2}$ applicator.

\begin{tabular}{|c|c|c|c|c|c|c|c|c|}
\hline & \multicolumn{2}{|c|}{$8 \mathrm{MeV}$} & \multicolumn{2}{|c|}{$10 \mathrm{MeV}$} & \multicolumn{2}{|c|}{$12 \mathrm{MeV}$} & \multicolumn{2}{|c|}{$14 \mathrm{MeV}$} \\
\hline & $\begin{array}{c}\text { Monte } \\
\text { Carlo } \\
(\mathrm{mm})\end{array}$ & $\begin{array}{l}\text { Measure- } \\
\text { ment (mm) }\end{array}$ & $\begin{array}{c}\text { Monte } \\
\text { Carlo } \\
(\mathrm{mm})\end{array}$ & $\begin{array}{l}\text { Measure- } \\
\text { ment }(\mathrm{mm})\end{array}$ & $\begin{array}{c}\text { Monte } \\
\text { Carlo } \\
(\mathrm{mm})\end{array}$ & $\begin{array}{l}\text { Measure- } \\
\text { ment }(\mathrm{mm})\end{array}$ & $\begin{array}{l}\text { Monte } \\
\text { Carlo } \\
\text { (mm) }\end{array}$ & $\begin{array}{l}\text { Measure- } \\
\text { ment }(\mathrm{mm})\end{array}$ \\
\hline $\mathbf{Z}_{\max }$ & 19.00 & 19.00 & 22.00 & 22.00 & 27.00 & 27.00 & 29.00 & 29.00 \\
\hline $\mathbf{R}_{90}$ & 25.12 & 24.93 & 30.02 & 29.82 & 35.41 & 35.52 & 40.45 & 40.15 \\
\hline $\mathbf{R}_{80}$ & 27.78 & 27.59 & 33.41 & 33.30 & 40.09 & 39.65 & 45.04 & 44.41 \\
\hline $\mathbf{R}_{50}$ & 32.64 & 32.70 & 39.22 & 39.63 & 46.86 & 46.25 & 52.28 & 52.16 \\
\hline
\end{tabular}

$Z_{\max }$ : depth where the dose is maximum

$\mathrm{R}_{90}$ : In this depth, the dose is $90 \%$ of the maximum dose

$\mathrm{R}_{80}:$ In this depth, the dose is $80 \%$ of the maximum dose

$\mathrm{R}_{50}:$ In this depth, the dose is $50 \%$ of the maximum dose 
Table 2: The results for the difference between measurements and calculations, for 8 - $14 \mathrm{MeV}$, for $R_{50^{\prime}} R_{80^{\prime}}$ and $R_{90}$, for the $10 \times 10$ $\mathrm{cm}^{2}$ applicator.

\begin{tabular}{lccc} 
Energy & $\begin{array}{c}\text { Difference } \\
\text { in } \mathbf{R}_{\mathbf{5 0}} \mathbf{( \% )}\end{array}$ & $\begin{array}{c}\text { Difference } \\
\text { in } \mathbf{R}_{\mathbf{8 0}}(\mathbf{\%})\end{array}$ & $\begin{array}{c}\text { Difference } \\
\text { in } \mathbf{R}_{\mathbf{9 0}}(\mathbf{\%})\end{array}$ \\
\hline $8 \mathrm{MeV}$ & 0.18 & 0.68 & 0.75 \\
\hline $10 \mathrm{MeV}$ & 1.03 & 0.32 & 0.61 \\
\hline $12 \mathrm{MeV}$ & 1.30 & 1.09 & 0.3 \\
\hline $14 \mathrm{MeV}$ & 0.22 & 1.39 & 0.74
\end{tabular}

used in radiotherapy performed with the linac. Another goal was to validate the simulations by comparing the simulation results with the measurements. The geometrical characteristics of the accelerator were provided by the manufacturer. The dose profiles for the $10 \times$ $10 \mathrm{~cm}^{2}$ and $20 \times 20 \mathrm{~cm}^{2}$ applicators at different depths were obtained and plotted. The maximal value of the MC statistical uncertainty was $3.2 \%$ in these simulations. The results suggest a good settlement between measurements and simulations.

When gamma index was plotted against the dose profile, most gamma index values were found to be below 1, except those for the dose profile curve of the 14-MeV-energy beam. For a beam of this energy, some data points had gamma index values above 1 . The disagreement might stem from a small inexactitude in modelling the scattering foil which yields a wrong prediction of the scattered dose. The differences between the measured and simulated $\mathrm{Z}_{\max }, \mathrm{R}_{90}, \mathrm{R}_{80}$ and $\mathrm{R}_{50}$ values were negligible. The precision of simulations for these depths was $\sim 2 \%$. The difference between MC-simulated and measured values could be explained by the absence of bremsstrahlung photons.

The simulation software can be used for electron modes of Siemens Primus linac when direct experimental measurements are not feasible. The results exhibit the MC technique can be used to accurately compute electron beam data in most situations, where finite-size data sets are involved, yielding a better outcome compared with previous studies. Upon extensive literature search to compare the gamma function values in this work to those reported in other articles, the only article found was by Bahreyni et al. In the study by Bahreyni et al., only percentage depth dose values were evaluated and the doe profile were not examined. To the best of our knowledge, no study has compared dose profile data from MC calculation and measurement using gamma function in electron mode of this device (Siemens Linac)

\section{Acknowledgment}

The authors would like to thank Mrs. Akbari for providing the data, as well as the Hakim Sabzevari University for great help.

\section{Conflict of Interest}

None

\section{References}

1. Vega-Carrillo HR, Martinez-Ovalle SA, Lallena AM, Mercado GA, Benites-Rengifo JL. Neutron and photon spectra in LINACs. Appl Radiat Isot. 2012;71:75-80. doi.org/10.1016/j.apradiso.2012.03.034. PubMed PMID: 22494894.

2. Hogstrom KR, Almond PR. Review of electron beam therapy physics. Phys Med Biol. 2006;51:R455-89. doi.org/10.1088/0031-9155/51/13/R25. PubMed PMID: 16790918.

3. Xing A. Dosimetric Investigation of Electron Arc Therapy Delivered Using Siemens Electron Arc Applicator with a Trapezoidal Aperture. Christchurch: University of Canterbury; 2007.

4. Khan FM. The physics of radiotherapy. $3^{\text {th }}$ ed. Philadelphia: Lippincott Williams \& Wilktins; 2003. p.297-356.

5. Rogers D. Monte Carlo techniques in radiotherapy. Physics in Canada. 2002;58:63-71.

6. Ma C-M, Jiang SB. Monte Carlo modelling of electron beams from medical accelerators. Physics in Medicine \& Biology. 1999;44:R157. doi. org/10.1088/0031-9155/44/12/201.

7. Andreo P. Monte Carlo techniques in medical radiation physics. Phys Med Biol. 1991;36:861-920. doi.org/10.1088/0031-9155/36/7/001. PubMed PMID: 1886926. 
8. Zaidi H. Relevance of accurate Monte Carlo modeling in nuclear medical imaging. Med Phys. 1999;26:574-608. doi.org/10.1118/1.598559. PubMed PMID: 10227362.

9. Dechsupa P. Modelling $6 \mathrm{MeV}$ Electron Beam from Medical Linear Accelerator Using Monte Carlo Simulation. Chang Wat Nakhon Pathom: Mahidol University; 2009.

10. Sheikh-Bagheri D, Rogers DW, Ross CK, Seuntjens JP. Comparison of measured and Monte Carlo calculated dose distributions from the NRC linac. Med Phys. 2000;27:2256-66. doi.org/10.1118/1.1290714. PubMed PMID: 11099192

11. Antolak JA, Bieda MR, Hogstrom KR. Using Monte Carlo methods to commission electron beams: a feasibility study. Med Phys. 2002;29:771-86. doi.org/10.1118/1.1469626. PubMed PMID: 12033573.

12. Kapur A, Ma CM, Mok EC, Findley DO, Boyer AL. Monte Carlo calculations of electron beam output factors for a medical linear accelerator. Phys Med Biol. 1998;43:3479-94. doi.org/10.1088/00319155/43/12/007. PubMed PMID: 9869026.

13. Nedaie HA, Mosleh-Shirazi M, Shariary M, Gharaati $\mathrm{H}$, Allahverdi M. Monte Carlo study of electron dose distributions produced by the elekta precise linear accelerator. Reports of Practical Oncology \& Radiotherapy. 2006;11:287-92. doi.org/10.1016/ S1507-1367(06)71074-4.

14. Waters LS. MCNPX user's manual, Version 2.7.0. Report LA-UR-11-02295: Los Alamos National Laboratory; 2011.

15. Mohammadi N, Miri-Hakimabad H, Rafat-Motavlli L, Akbari F, Abdollahi S. Neutron spectrometry and determination of neutron contamination around the 15 MV Siemens Primus LINAC. Journal of Radio- analytical and Nuclear Chemistry. 2015;304:10018. doi.org/10.1007/s10967-015-3944-5.

16. Siemens Company. Siemens Medical Systems. Available at: [https://www.siemens.com].

17. Chetty IJ, Curran B, Cygler JE, DeMarco JJ, Ezzell G, Faddegon BA, et al. Report of the AAPM Task Group No. 105: Issues associated with clinical implementation of Monte Carlo-based photon and electron external beam treatment planning. Med Phys. 2007;34:4818-53. doi.org/10.1118/1.2795842. PubMed PMID: 18196810.

18. Toossi MTB, Ghorbani M, Akbari F, Sabet LS, Mehrpouyan M. Monte Carlo simulation of electron modes of a Siemens Primus linac (8,12 and $14 \mathrm{MeV}$ ). Journal of Radiotherapy in Practice. 2013;12:3529. doi.org/10.1017/S1460396912000593.

19. Low DA, Harms WB, Mutic S, Purdy JA. A technique for the quantitative evaluation of dose distributions. Med Phys. 1998;25:656-61. doi. org/10.1118/1.598248. PubMed PMID: 9608475.

20. Bak J, Choi JH, Kim JS, Park SW. Modified dose difference method for comparing dose distributions. J Appl Clin Med Phys. 2012;13:3616. doi. org/10.1120/jacmp.v13i2.3616. PubMed PMID: 22402379. PubMed PMCID: 5716408.

21. Depuydt T, Van Esch A, Huyskens DP. A quantitative evaluation of IMRT dose distributions: refinement and clinical assessment of the gamma evaluation. Radiother Oncol. 2002;62:309-19. doi. org/10.1016/S0167-8140(01)00497-2. PubMed PMID: 12175562.

22. Schreiber EC, Faddegon BA. Sensitivity of largefield electron beams to variations in a Monte Carlo accelerator model. Phys Med Biol. 2005;50:76978. doi.org/10.1088/0031-9155/50/5/003. PubMed PMID: 15798253. 